\title{
Fabrication, Structural Characterization and Optical Properties of the Flower-Like $\mathrm{ZnO}$ Nanowires
}

\author{
L. Feng, A. LiU*, Y. Ma, M. Liu And B. Man \\ College of Physics and Electronics, Shandong Normal University, Jinan 250014, P.R. China
}

(Received January 10, 2010; in final form March 5, 2010)

\begin{abstract}
Multipod flower-like zinc oxide $(\mathrm{ZnO})$ nanowires have been successfully synthesized on $\mathrm{Si}(111)$ substrates using a pulsed laser deposition prepared Zn film as "self-catalyst" by the simple thermal evaporation oxidation of the metallic zinc powder at $850^{\circ} \mathrm{C}$ without any other catalysts or additives. The pre-deposited Zn films by pulsed laser deposition on the substrates can promote the formation of the $\mathrm{ZnO}$ nuclei effectively. Also it can further advance the growth of the flower-like $\mathrm{ZnO}$ nanowires accordingly. X-ray diffraction, scanning electron microscope, high-resolution transmission electron microscopy, Fourier transform infrared spectrum, and photoluminescence were used to analyze the structure, morphology, composition and optical properties of the as-synthesized products. The results demonstrate that the nanowires were single crystalline with hexagonal wurzite structure, grown along the [0001] in the $c$-axis direction. Room temperature photoluminescence spectrum of the $\mathrm{ZnO}$ nanowires shows a nearband-edge ultraviolet emission (peak at $\approx 384 \mathrm{~nm}$ ) and a deep-level green emission (peak at $\approx 513 \mathrm{~nm}$ ). In addition, the growth mechanism of the flower-like $\mathrm{ZnO}$ nanowires is discussed in detail.
\end{abstract}

PACS numbers: 81.07.Bc, 81.05.Dz, 81.10.Aj

\section{Introduction}

In recent years, controlled synthesis of compound semiconductor nanostructures has attracted considerable interest in material fields, owing to that the properties of these materials depend mainly on their specific shapes, sizes and structures [1]. The interest in $\mathrm{ZnO}$ nanostructures is fueled and fanned by its prospects in optoelectronics applications because of its typical wide direct band gap $(3.37 \mathrm{eV})$ with a large exciton binding energy $(60 \mathrm{eV})$ at room temperature [2]. To date, the $\mathrm{ZnO}$ nanostructured materials, such as nanorods [3], nanotubes [4], nanowires [5], nanobelt [6] and nanobridge [7], have been successfully synthesized and have received much attention due to their novel physical properties and potential applications in nanodevices and nanosensors [8]. Such nanostructures would play an important role in understanding the role of dimensionality and size in optical [9], electrical [10], mechanical [11] and magnetic properties [12, 13]. Among them, the $\mathrm{ZnO}$ nanowires with a high surface-to-volume ratio have received particular attention and are expected to display significant properties. The $\mathrm{ZnO}$ nanowires have some obvious advantages over the $\mathrm{ZnO}$ bulk crystals and thin films due to the size confinement effects for the carriers and excitons [14]. Particularly, the stronger and more stable exciton effects at

* corresponding author; e-mail: lah1120@gmail.com room temperature are very important in the light emission diodes (LED) and laser diodes (LD) [15, 16]. Moreover, the growth technologies of the $\mathrm{ZnO}$ nanowires are much simpler than that of the $\mathrm{ZnO}$ thin film. Therefore, various methods have been developed to fabricate the $\mathrm{ZnO}$ nanowires, for instance, chemical vapor deposition (CVD) [17], metal-organic chemical vapor deposition (MOCVD) [18], hydrothermal process [19], metal catalyzed vapor-liquid-solid process [20], aqueous solution method [21], pulsed laser deposition (PLD) [22], electrochemical deposition [23], microwave-assisted route [24], and ultrasonic spray pyrolysis [25]. However, catalysts usually have to be used in those methods during the synthesis of the $\mathrm{ZnO}$ nanowires The drawback is that the remains of the foreign catalyst in the products may influence some applications of the $\mathrm{ZnO}$ nanowires.

In this paper, we reported a simple synthesis method for the $\mathrm{ZnO}$ nanowires, which overcomes the drawbacks of previous methods. The flower-like $\mathrm{ZnO}$ nanowires were synthesized by simple thermal evaporating of high purity $\mathrm{Zn}$ powders onto a quartz tube at the temperature of $850^{\circ} \mathrm{C}$ without introducing any external catalysts approach. Especially, in our experiment, a layer of $\mathrm{Zn}$ film is firstly pre-deposited on the $\mathrm{Si}(111)$ substrates by PLD before the thermal evaporating process. The PLD $\mathrm{Zn}$ film can promote the growth of the $\mathrm{ZnO}$ nanowires. The as-synthesized products are single-crystalline $\mathrm{ZnO}$ nanowires. This growth method allows a continuous synthesis and can produce $\mathrm{ZnO}$ nanowires with relatively 
high purity and low cost. Accordingly, it is probably useful for commercial-scale production. In addition, the possible growth mechanism and the optical property of the $\mathrm{ZnO}$ nanowires are also discussed in brief.

\section{Experimental process}

Firstly, $\mathrm{Si}(111)$ substrates were washed with absolute ethyl alcohol, and then ultrasonically cleaned in acetone, absolute ethyl alcohol, and deionized water for $30 \mathrm{~min}$ in sequence.

Secondly, a thin layer of $\mathrm{Zn}$ films was deposited on Si(111) substrates by PLD. The PLD apparatus and the experimental methods have been described in detail elsewhere [26]. High purity metal zinc $(99.99 \%)$ with a diameter of $6 \mathrm{~mm}$ served as a target. The deposition chamber was evacuated by turbomolecular pump yielding typical base pressures of $3 \times 10^{-4} \mathrm{~Pa}$. The Q-switched Nd:YAG laser $(\lambda=1064 \mathrm{~nm})$ was used to ablate the zinc target. The laser energy, the repetition rate, and the argon background pressure were set to be $100 \mathrm{~mJ}, 10 \mathrm{~Hz}$, and $1.33 \mathrm{~Pa}$, respectively. The substrates are $\mathrm{Si}(111)$ and the distance between the target and the substrates is $40 \mathrm{~mm}$. For the Zn target ablated and thin film fabricated evenly, Zn target rotated clockwise and substrate rotated anticlockwise with a frequency of $7 \mathrm{rpm}$. The deposition time is $30 \mathrm{~min}$ and the growth temperature is $100^{\circ} \mathrm{C}$. The film thickness was measured to be approximately $100 \mathrm{~nm}$.

Finally, both the as-deposited Zn films by PLD and the high purity metallic Zn powder (99.99\%) were inserted into the conventional horizontal quartz tube furnace (L4513II-2/QWZ) together. The Zn powder as the source material was placed in a high-temperature region of a quartz boat covered by another two-end open quartz cap. The Zn-coated $\mathrm{Si}(111)$ substrates prepared at the second step were placed in the low temperature region of the same boat. The distance between the $\mathrm{Zn}$ powder source and the Si substrate was about $10 \mathrm{~mm}$. After heating the tube furnace to $850^{\circ} \mathrm{C}$ at a rate of $50-100^{\circ} \mathrm{C} / \mathrm{min}$, the nitrogen gas with purity of $99.999 \%$ was introduced into the system with a flow of $200 \mathrm{sccm}$ (standard cubic centimeters per minute) for $5 \mathrm{~min}$ to remove the residual air. Then the quartz boat loaded with the substrates and the source material were pushed into the center constant temperature region of the furnace. After the quartz boat was loaded into the furnace, a flow of mixture gas $\left[\mathrm{O}_{2}: \mathrm{Ar}=1: 15\right.$ (by volume, $99.999 \%$ pure) $]$ with the flow rate of $200 \mathrm{sccm}$ was introduced to the system until the end of the reaction. The temperature of the Si substrate is about $700{ }^{\circ} \mathrm{C}$ in the system during the growth process. The reaction time was $20 \mathrm{~min}$. After that, the reaction system was drawn out immediately and some white fluffy-like products were observed on the whole surface of the substrate. The products were collected for characterizations.

The morphology and structure properties of products were characterized and analyzed by X-ray diffraction (Rigaku D/max-rB Cu $K_{\alpha}$, XRD), scanning electron mi- croscopy (Hitachi S-570, SEM), high resolution transmission electron microscopy (JEOL JEM2100, HRTEM) and Fourier transform infrared spectrum (TENSOR27, FTIR). The room-temperature photoluminescence (PL) spectrum of the products was measured using Edinburgh Instruments FLS920 steady-state fluorescence spectrometer (U.K.) with Xe lamp as the excitation light source (with a wavelength of $325 \mathrm{~nm}$ ).

\section{Results and discussions}

\subsection{XRD analysis}

The crystal structure of the as-synthesized products was characterized by XRD. Figure 1 shows a typical XRD pattern of the as-synthesized products. The results show that all the diffraction peaks in the pattern can be easily indexed as the pure hexagonal phase $\mathrm{ZnO}$ (wurtzite-type, space group: $P 63 \mathrm{mc}$ ) with calculated lattice parameters of $a=3.244 \AA, c=5.198 \AA$, which is in good agreement with the reported standard values (JCPDS No. 36-1451). Compared with the standard diffraction patterns, no diffraction peaks of $\mathrm{Zn}$ or other impurities were observed in the spectrum, which indicates excellent crystal quality of the products. Furthermore, the clear and sharp peaks also revealed that the $\mathrm{ZnO}$ nanowires possess a high crystalline quality.

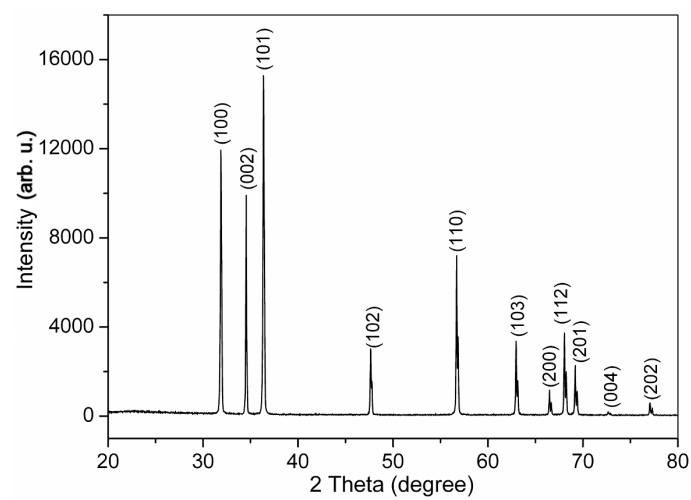

Fig. 1. X-ray diffraction pattern of the multipod flower-like $\mathrm{ZnO}$ nanowires synthesized at $850^{\circ} \mathrm{C}$.

\subsection{SEM analysis}

Figure 2 reveals the representative SEM images of the as-synthesized products at different magnifications. Figure 2a, the panoramic morphology of the products, showed that the high yield accumulated $\mathrm{ZnO}$ nanowires were formed and distributed randomly on the substrate. It can be seen that most of the $\mathrm{ZnO}$ nanowires exhibited a radial multipod morphology having several legs and only a few tetrapod-like $\mathrm{ZnO}$ nanowires. From Fig. 2b and $\mathrm{c}$ it is clearly shown that the nanowires have a straight, smooth, pencil-like shape. The legs were connected to a junction which can be regarded as a central nucleus, forming a radial flower-like structure. The 

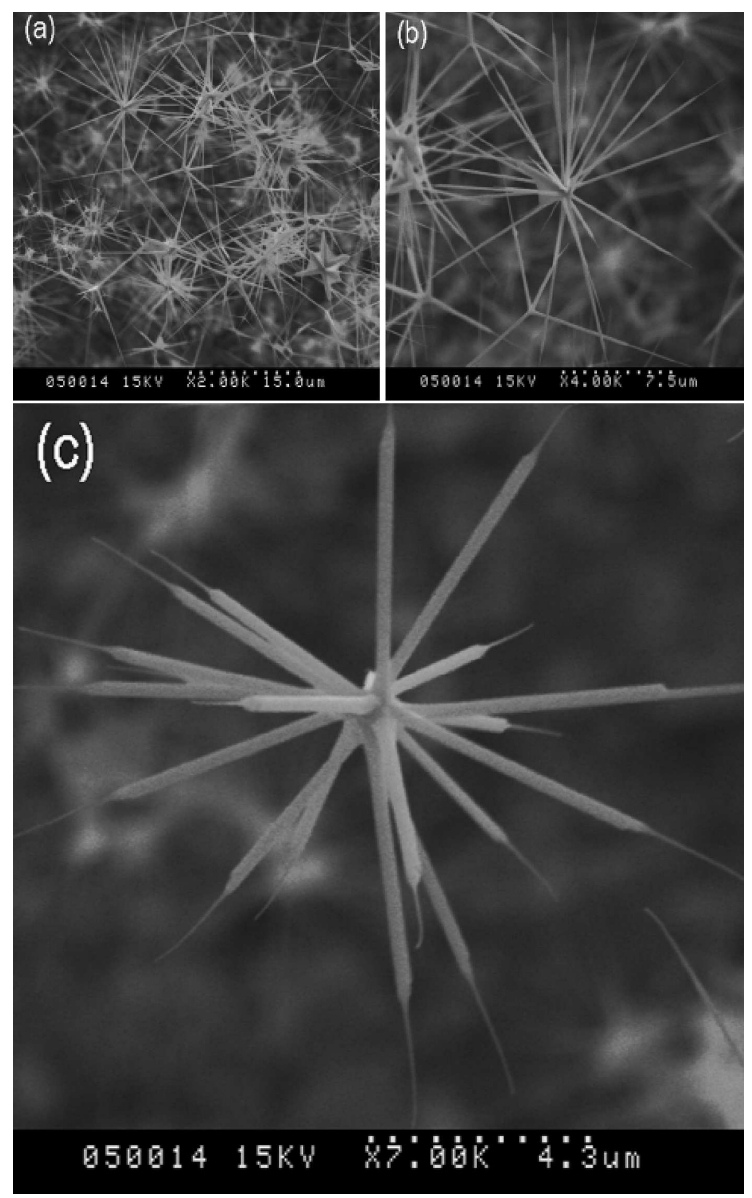

Fig. 2. Typical SEM images of the multipod flower-like $\mathrm{ZnO}$ nanowires at different magnifications: (a) $2000 \times$, (b) $4000 \times$, (c) $7000 \times$.

central nucleus of the radial multipod flower-like $\mathrm{ZnO}$ nanowires is obviously bigger than those of the tetrapod nanowires. Most of the nanowires have a rod-like root and exhibit a sharp needle-like tip. The root diameters of the nanowires are in the range of $200-400 \mathrm{~nm}$, while the tips have an average diameter about $40 \mathrm{~nm}$. The length of the $\mathrm{ZnO}$ nanowires is about several micrometers. Furthermore, a small quantity of the $\mathrm{ZnO}$ lamellar crystal were also observed at some roots of the nanowires. Comparing the differences in the nucleus sizes, the essence of the legs of the tetrapod nanowires and those of the multipod nanowires are the same, which implies that they have the same growth mechanism [27]. The results indicate that the morphological differences between the tetrapod nanowires and the multipod nanowires might be a consequence of the difference in the size of the nucleus.

\subsection{HRTEM analysis}

To further understand the structural characteristics of the flower-like $\mathrm{ZnO}$ nanowires, HRTEM micrograph and selected area electron diffraction (SAED) pattern of the products were surveyed. Figure 3 shows the HRTEM images of the single $\mathrm{ZnO}$ nanowire, the visible lattice images illustrate that the nanowire is single-crystal in nature. The interplanar distance accurately measured is $0.26 \mathrm{~nm}$, which corresponds to the distance between the two adjacent (0002) crystal planes of hexagonal $\mathrm{ZnO}$. The (0002) planes are perpendicular to the growth direction of the $\mathrm{ZnO}$ nanowires, which confirms that the $\mathrm{ZnO}$ nanowires only grow along the $c$-axis direction. The inset in the upper-left-hand corner is the SAED pattern of single nanowire, which can be indexed to the diffraction of wurtzite $\mathrm{ZnO}$ crystal along the [0001] direction. Meanwhile, it also confirms that the as-synthesized $\mathrm{ZnO}$ nanowires are of single crystal structure.

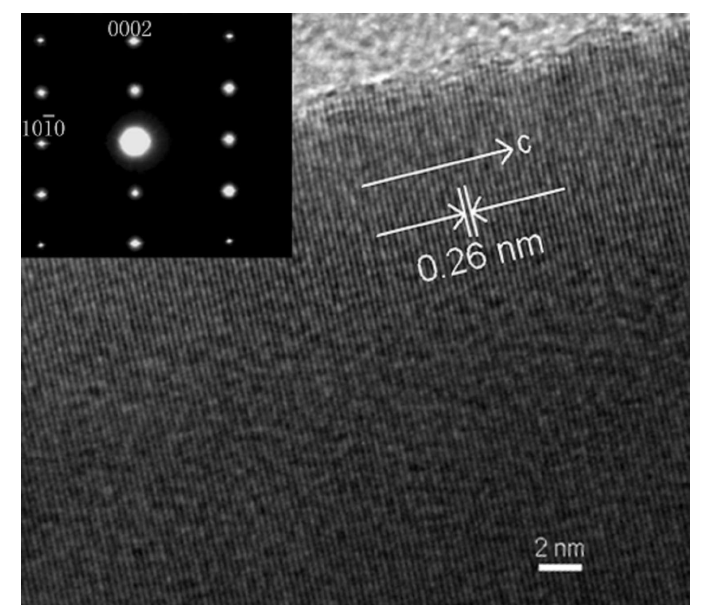

Fig. 3. HRTEM lattice image of the single $\mathrm{ZnO}$ nanowire. The upper-left-hand is the corresponding SAED image.

\subsection{FTIR analysis}

The products were mixed with potassium bromide (KBr) in the ratio of 1:100. The background spectrum recorded using $\mathrm{KBr}$ was subtracted from the products spectrum. Figure 4 exhibits FTIR spectrum of the $\mathrm{ZnO}$ nanowires. The absorption region from 400 to $2000 \mathrm{~cm}^{-1}$ generally represents the fingerprint region of the materials, which are unique in characteristics. The spectrum contains four prominent absorption bands. The band at $440.13 \mathrm{~cm}^{-1}$ corresponds to the asymmetric stretching mode of the as-synthesized wurtzite $\mathrm{ZnO}$ nanowires [28]. The absorption band around $548.46 \mathrm{~cm}^{-1}$ is the typical reference spectra of the pure $\mathrm{ZnO}$ powders often shown in [29]. The two bands at $1384.67 \mathrm{~cm}^{-1}$ and $1633.63 \mathrm{~cm}^{-1}$ are associated with $\mathrm{Zn}-\mathrm{O}$ stretching vibration in wurtzite hexagonal-type $\mathrm{ZnO}$ crystal [30], which revealed that the products were hexagonal $\mathrm{ZnO}$ crystals. No other peaks observed in the spectrum confirms that the synthesized products are $\mathrm{ZnO}$ alone, which also correspond to the XRD.

\subsection{Discussion of growth mechanism}

According to the above analysis, we can infer the possible growth mechanism for the formation of the multipod 


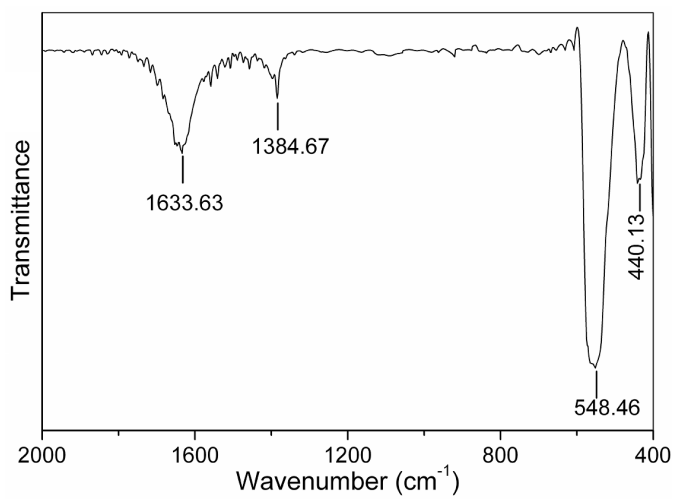

Fig. 4. FTIR spectrum of the multipod flower-like $\mathrm{ZnO}$ nanowires.

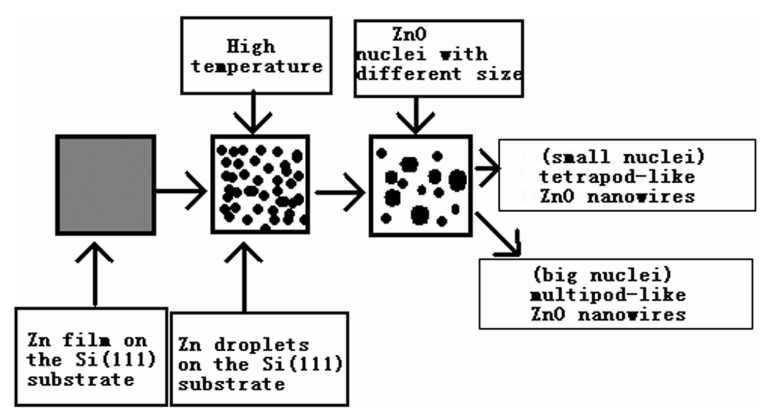

Fig. 5. Schematic illustration of the growth mechanism of the $\mathrm{ZnO}$ nanowires.

flower-like $\mathrm{ZnO}$ nanowires. The nanowires growth does not follow the conventional metal-catalytic VLS mechanism [31], but can be conceived as "self-catalyst" VLS growth mode [32]. The whole process is illustrated in Fig. 5. When the furnace temperature mounted into $850^{\circ} \mathrm{C}$, much higher than the melting point of metallic zinc powder (the melting point of $\mathrm{Zn}=419.5^{\circ} \mathrm{C}$ ), the zinc vapors were produced from the source material. Because the amount of oxygen is deficient in our experiment, some suboxides $\left(\mathrm{ZnO}_{x}, x<1\right)$ were also easily formed correspondingly. Due to the fact that $\mathrm{Zn}$ and $\mathrm{Zn}$-suboxides $\left(\mathrm{ZnO}_{x}, x<1\right)$ have a low melting temperature (approximately $419^{\circ} \mathrm{C}$ ) [33], $\mathrm{Zn}$ and $\mathrm{ZnO}_{x}$ should be in vapor phases at the beginning of our experiment.

In the meantime, because the substrate temperature is higher than the melting point of $\mathrm{Zn}$, the $\mathrm{Zn}$ films pre-deposited on the substrates are melted and aggregated to form the micro-sized Zn droplets on the substrate surface. Then, the oxygen react with the $\mathrm{Zn}$ droplets and form the $\mathrm{ZnO}$ nuclei on the substrate surface. Due to the flowing gas circulation, the $\mathrm{Zn}(\mathrm{g})$ or $\mathrm{ZnO}_{x}(\mathrm{~g})$ vapor was transported by argon and condensed on the Si substrates located at a low temperature region. After that, the deposited $\mathrm{Zn}$ or $\mathrm{ZnO}_{x}$ also turned into liquid phase (l) $\mathrm{Zn}$ or $\mathrm{ZnO}_{x}(1, x<1)$ droplets. These formed $\mathrm{Zn}$ or $\mathrm{ZnO}_{x}$ droplets migrated and merged with the original $\mathrm{Zn}$ droplets on the substrate surface, and then the incorpo- rated droplets continued to absorb oxygen vapor around and formed more larger $\mathrm{ZnO}$ nuclei. So "self-catalyst" VLS growth has already begun to take effect during this initial growth period. The main reaction taking place in our experiment can be expressed as follows (g, l, s stand for gaseous, liquid, solid, respectively):

$$
\begin{aligned}
& \mathrm{Zn}(\mathrm{s}) \rightarrow \mathrm{Zn}(\mathrm{g}), \\
& \mathrm{Zn}(\mathrm{g})+\mathrm{O}_{2}(\mathrm{~g}) \rightarrow \mathrm{ZnO}_{x}(\mathrm{~g}), \\
& \mathrm{Zn}(\mathrm{g}) \rightarrow \mathrm{Zn}(\mathrm{l}), \quad \mathrm{ZnO}_{x}(\mathrm{~g}) \rightarrow \mathrm{ZnO}_{x}(\mathrm{l}), \\
& \mathrm{Zn}(\mathrm{l})+\mathrm{O}_{2}(\mathrm{~g}) \rightarrow \mathrm{ZnO}(\mathrm{s}), \\
& \mathrm{ZnO}_{x}(\mathrm{l})+\mathrm{O}_{2}(\mathrm{~g}) \rightarrow \mathrm{ZnO}(\mathrm{s}) .
\end{aligned}
$$

In addition, the nucleation plays a key role in the growth of the flower-like $\mathrm{ZnO}$ nanowires in our experiment. According to the octa-twin nucleus model, $\mathrm{ZnO}$ nuclei formed in the atmosphere containing oxygen are octahedral nuclei [34]. The octahedral nuclei were considered to lead to the formation of the tetrapod nanowires [35]. Due to that the sizes of these aggregated $\mathrm{ZnO}$ nuclei were larger than the previously formed nuclei, the insufficiency of oxygen and the high temperature will make the accumulation of these aggregated nuclei to a multiple facets possible. It finally led to the formation of the polyhedral $\mathrm{ZnO}$ nuclei rather than octahedral nuclei. However, during this process, some small nuclei did not merge with other nuclei, which still kept the octahedron morphology and formed finally some tetrapod nanowires. It manifests that the formation of the multipod $\mathrm{ZnO}$ nanowires nuclei on the $\mathrm{Zn}$-coated substrates is owing to the merging and growth of the polyhedral $\mathrm{ZnO}$ nuclei. Hence, the pre-deposited $\mathrm{Zn}$ films on the substrates can effectively promote the formation of the polyhedral $\mathrm{ZnO}$ nuclei. Those $\mathrm{ZnO}$ nuclei provide the energetically favored sites for the further growth of the multipod flower-like $\mathrm{ZnO}$ nanowires.

Furthermore, in the early stages of the reaction, it is probable that some $\mathrm{ZnO}$ nuclei or initially formed tiny single crystals are also easy to aggregate together under the driving forces of high surface energy, electrostatic force, and so forth [36]. Then each $\mathrm{ZnO}$ nucleus in the aggregate grows anisotropically along the $c$-axis. The aggregates finally become the flower-like nanowires assemblies. So, the obtained multipod $\mathrm{ZnO}$ nanowires are made up of several single crystals nanowires stretching radially from the center nuclei along $c$-axis directions. On the other hand, it is known that $\mathrm{ZnO}$ crystal has the wurtzite polar crystal structure which has a hexagonal unit cell with space group P6mc. The oxygen anions and $\mathrm{Zn}$ cations form a tetrahedral unit. The structure of the $\mathrm{ZnO}$ can be simply described as a number of alternating planes composed of tetrahedrally coordinated $\mathrm{O}^{2-}$ and $\mathrm{Zn}^{2+}$, stacked alternatively along the $c$-axis.

Wurtzite structure model of the $\mathrm{ZnO}$ is shown in Fig. 6 . As can be seen in Fig. 6, each Zn atom on the $\{10 \overline{1} 0\}$ prismatic faces parallel to the $c$-axis is two-coordinated $\mathrm{Zn}$, whereas the $\mathrm{Zn}$ atom on the (0001) facet is one- or three-coordinated $\mathrm{Zn}$. The inherent asymmetry along the 


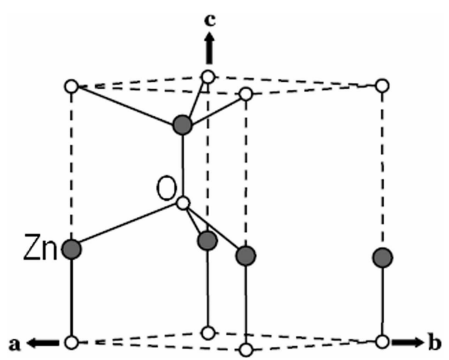

Fig. 6. Wurtzite structure model of the $\mathrm{ZnO}$.

$c$-axis leads to the anisotropic growth of the $\mathrm{ZnO}$ crystallites [37]. The formation of the multipod flower-like $\mathrm{ZnO}$ nanowires crystals is attributed to the difference in the growth rate of the various crystal facets. According to the lowest surface energy principle, the $\mathrm{ZnO}$ nuclei will be exposed at the crystal surfaces with the lowest energy [38]. Then the ZnO nanowires sprouted from these nuclei surfaces and grew along the [0001] direction because the surface energy of the (0002) facet is the lowest. According to the $\mathrm{ZnO}$ crystal growth mode, the growth rate along the [0001] direction is faster than along any other directions [39]. So, the growth along the [0001] direction is a dominating growth facet compared to other growth facets. Therefore, the multipod flower-like $\mathrm{ZnO}$ nanowires are finally formed. In our synthesized process, the multipod flower-like $\mathrm{ZnO}$ nanowires exhibited a preferential growth in the [0001] direction which also corresponded to the HRTEM and SAED patterns. In addition, the $\mathrm{ZnO}$ lamellar crystal is also observed at some roots of the nanowires due to the high temperature and the high super-saturation of the lateral growth.

\section{6. $P L$ spectrum analysis}

Figure 7 shows the measurement of PL spectrum at room temperature of the products. The nanowires show two emission peaks, a strong ultraviolet (UV) band located at $\approx 384 \mathrm{~nm}$, a green emission band centered at $\approx 513 \mathrm{~nm}$. The UV emission originates from the excitonic recombination corresponding to the near band-edge emission of band gap $\mathrm{ZnO}$. Moreover, the enhancement in UV emission intensity of the room temperature PL in our result was due to the improvement in the crystal quality of the flower-like $\mathrm{ZnO}$ nanorods.

Bagnall et al. [40] revealed that the improvement of crystal quality (decrease of impurities, and structure defects such as oxygen vacancies and zinc interstitials) can lead to a high near band-edge emission to deep-level emission ratio, resulting in the detectable UV emissions at room temperature. HRTEM image in Fig. 3 proved that the $\mathrm{ZnO}$ nanowires are single crystal structure with a low density of structural defects, an important factor for the observed UV emission at room temperature. Moreover, we observed a green light emission peak at $\approx 513 \mathrm{~nm}$, commonly referred to a deep-level or trap-state emission. The green transition has been attributed to the

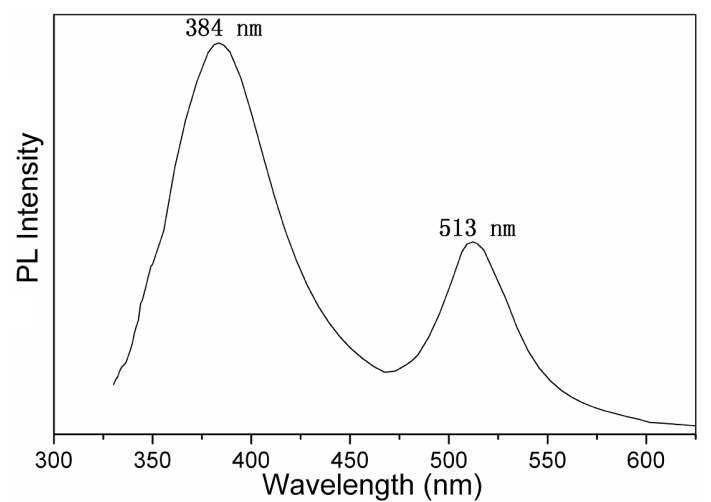

Fig. 7. Room temperature PL spectrum of the multipod flower-like $\mathrm{ZnO}$ nanowires.

single oxygen vacancy in the $\mathrm{ZnO}$ nanowires and the emission results from the radiative recombination of a photo-generated hole with an electron occupying of oxygen vacancy $\left(\mathrm{V}_{\mathrm{O}}\right)$ [41]. At higher temperature the number of molten $\mathrm{Zn}$ atoms increases, combined with oxygen to form $\mathrm{ZnO}$. To maintain the growth of nanostructures there should be a balance between the melting rate of $\mathrm{Zn}$ and the growth rate of $\mathrm{ZnO}$. Since higher temperature requires more oxygen for the growth of nanostructures, then the constant flow rate of oxygen even at higher temperature will lead to oxygen deficiency. In our experiment, because the $\mathrm{ZnO}$ nanowires are fabricated at $850{ }^{\circ} \mathrm{C}$, a quantity of oxygen vacancies can also easily be produced. Thus, the green emission at $\approx 513 \mathrm{~nm}$ would be a result of the existence of the oxygen vacancies in the $\mathrm{ZnO}$ nanowires. Therefore, it is appropriate to conclude that there are a number of oxygen vacancies in the $\mathrm{ZnO}$ nanowires, and some defects could exist in the $\mathrm{ZnO}$ nuclei. Therefore, we expect that the $\mathrm{ZnO}$ nanowires with strengthened green light emission would be a promising material for applications in optoelectronic nanodevices.

\section{Conclusions}

In summary, the multipod flower-like $\mathrm{ZnO}$ nanowires were synthesized on Zn-coated $\mathrm{Si}(111)$ substrate through catalyst-free thermal evaporation in a tube furnace at $850^{\circ} \mathrm{C}$. The pre-deposited $\mathrm{Zn}$ films by PLD on the substrate can promote the growth of the multipod flower-like $\mathrm{ZnO}$ nanowires effectively. The growth of the multipod flower-like $\mathrm{ZnO}$ nanowires mainly depends on the size of the formed $\mathrm{ZnO}$ nuclei. XRD, SEM and HRTEM show that the nanowires exhibited a single-crystalline wurtzite hexagonal structure and preferentially oriented in the [0001] direction. The growth mechanism of the multipod flower-like $\mathrm{ZnO}$ nanowires can be explained by a self-catalytic VLS growth model. Room temperature PL spectra of the $\mathrm{ZnO}$ nanowires show a strong UV emission band located at $\approx 384 \mathrm{~nm}$ and a green emission band centered at $\approx 513 \mathrm{~nm}$, which was ascribed to the 
near band-edge emission and the deep-level emission, respectively. We believe that the green-light emission property of the multipod flower-like $\mathrm{ZnO}$ nanowires may open up new opportunities for fabricating the optoelectronic nanodevices, such as LED and LD.

\section{Acknowledgments}

The authors are grateful for the financial support of the National Natural Science Foundation of China (10474059), the Provincial Natural Science Foundation of Shandong (Y2007 A05) and The Project-Sponsorship by SRF for ROCS, SEM, P.R. China.

\section{References}

[1] J.M. Jang, C.R. Kim, H. Ryu, M. Razeghi, W.G. Jung, J. Alloys Comp. 463, 503 (2008).

[2] H. Xue, X.L. Xu, Y. Chen, G.H. Zhang, S.Y. Ma, Appl. Surf. Sci. 255, 1806 (2008).

[3] S. Baruah, J. Dutta, J. Cryst. Growth 311, 2459 (2009).

[4] L.G. Yu, G.M. Zhang, S.Q. Li, Z.H. Xie, D.Z. Guo, J. Cryst. Growth 299, 184 (2007).

[5] D.S. Kim, U. Gösele, M. Zacharias, J. Cryst. Growth 311, 3216 (2009).

[6] Z.L. Wang, Mater. Sci. Eng. R 64, 33 (2009).

[7] J.S. Lee, M.S. Islam, S. Kim, Nano Lett. 6, 1487 (2006).

[8] O. Lupan, G. Chai, L. Chow, Microelectron. J. 38, 1211 (2007).

[9] A. Dakhlaoui, M. Jendoubi, L.S. Smiri, A. Kanaev, N. Jouini, J. Cryst. Growth 311, 3989 (2009).

[10] S.W. Yoon, J.H. Seo, K.H. Kim, J.P. Ahn, T.Y. Seong, K.B. Lee, H. Kwon, Thin Solid Films 517, 4003 (2009).

[11] B. Wen, J.E. Sader, J.J. Boland, Phys. Rev. Lett. 101, 175502 (2008).

[12] G. Clavel, N. Pinna, D. Zitoun, Phys. Status Solidi A 204, 118 (2007).

[13] S. Deka, P.A. Joy, Solid State Commun. 142, 190 (2007).

[14] D. Stichtenoth, C. Ronning, T. Niermann, L. Wischmeier, T. Voss, C.J. Chien, P.C. Chang, Nanotechnology 18, 435701 (2007).

[15] J. Bao, M.A. Zimmler, F. Capasso, X. Wang, Z.F. Ren, Nano Lett. 6, 1719 (2006).

[16] E. Lai, W. Kim, P.D. Yang, Nano Res. 1, 123 (2008).

[17] S.W. Kim, S. Fujita, H.K. Park, B. Yang, H.K. Kim, D.H. Yoon, J. Cryst. Growth 292, 306 (2006).

[18] S.K. Mohanta, D.C. Kim, X.H. Zhang, C.B. Soh, A.M. Yong, H.K. Cho, S. Tripathy, J. Cryst. Growth 310, 5312 (2008).
[19] S.K. Tzeng, M.H. Hon, I.C. Leu, J. Cryst. Growth 311, 4510 (2009).

[20] S.Y. Li, C.Y. Lee, T.Y. Tseng, J. Cryst. Growth 247, 357 (2003).

[21] M. Wang, C.H. Ye, Y. Zhang, H.X. Wang, X.Y. Zeng, L.D. Zhang, J. Mater. Sci. Mater. Electron. 19, 211 (2008).

[22] Y.W. Song, S. Lee, S.Y. Lee, J. Cryst. Growth 310 , 4612 (2008)

[23] X.H. Wang, S. Liu, P. Chang, Y. Tang, Phys. Lett. A 372, 2900 (2008).

[24] M.S. Mohajerani, M. Mazloumi, A. Lak, A. Kajbafvala, S. Zanganeh, S.K. Sadrnezhaad, J. Cryst. Growth 310, 3621 (2008).

[25] M.T. Htay, Y. Hashimoto, N. Momose, K. Ito, J. Cryst. Growth 311, 4499 (2009).

[26] M. Liu, X.Q. Wei, Z.G. Zhang, G. Sun, C.S. Chen, C.S. Xue, H.Z. Zhuang, B.Y. Man, Appl. Surf. Sci. 252, 4321 (2006).

[27] X.M. Sun, X. Chen, Y.D. Li, J. Cryst. Growth 244, 218 (2002).

[28] S. Rasouli, S.J. Moeen, A.M. Arabi, I. Tehran, Prog. Color Colorants Coat. 2, 45 (2009).

[29] A. Matei, I. Cernica, O. Cadar, C. Roman, V. Schiopu, Int. J. Mater. Form. 1, 767 (2008).

[30] M. Chang, X.L. Cao, H.B. Zeng, L.D. Zhang, Chem. Phys. Lett. 446, 370 (2007).

[31] K.W. Kolasinski, Curr. Opin. Solid State Mater. Sci. 10, $182(2006)$.

[32] Q. Wan, K. Yu, T.H. Wang, C.L. Lin, Appl. Phys. Lett. 83, 2253 (2003).

[33] Y.W. Heo, V. Varadarajan, M. Kaufman, K. Kim, D.P. Norton, F. Ren, P.H. Fleming, Appl. Phys. Lett. 81, 3046 (2002).

[34] Y. Dai, Y. Zhang, Z.L. Wang, Solid State Commun. 126, 629 (2003).

[35] M. Shiojiri, C. Kaito, J. Cryst. Growth 52, 173 (1981).

[36] J. Xie, P. Li, Y.T. Li, Y.J. Wang, Y. Wei, Mater. Chem. Phys. 114, 943 (2009).

[37] B.M. Wen, Y.Z. Huang, J.J. Boland, J. Phys. Chem. C 112, 106 (2008).

[38] H. Iwanaga, M. Fujii, S. Takeuchi, J. Cryst. Growth 134, 275 (1993).

[39] Q.J. Yu, W.Y. Fu, C.L. Yu, H.B. Yang, R.H. Wei, M.H. Li, S.K. Liu, Y.M. Sui, Z.L. Liu, M.X. Yuan, G.T. Zou, J. Phys. Chem. C 111, 17521 (2007).

[40] D.M. Bagnall, Y.F. Chen, M.Y. Shen, Z. Zhu, T. Goto, T. Yao, J. Cryst. Growth 185, 605 (1998).

[41] K. Vanheusden, W.L. Warren, C.H. Seager, D.R. Tallant, J.A. Voigt, B.E. Gnade, J. Appl. Phys. 79, 7983 (1996). 